\title{
Increasing age at presentation for patients with ankylosing spondylitis
}

\begin{abstract}
An analysis of the age at first presentation was undertaken in patients with ankylosing spondylitis and mechanical back pain seen at the London Hospital department of rheumatology between 1952 and 1983 . There was a significant positive correlation with the calendar year of presentation in the patients with ankylosing spondylitis but a negative correlation in those with mechanical back pain. An increasing age at presentation in ankylosing spondylitis is likely to be due to an increasing age at disease onset-all anticipated biases would act in the opposite direction. This observation in a prospective study supports the findings of other studies using different epidemiological techniques.
\end{abstract}

There has been a series of epidemiological studies from developing countries suggesting that a significant proportion of patients who develop ankylosing spondylitis do so before the age of $16 .^{1-6}$ Most of these patients have been identified by a retrospective analysis of clinic records of patients attending tertiary referral centres. Similar studies from western centres, some undertaken over 30 years ago, have found that a smaller proportion of these patients develop juvenile onset ankylosing spondylitis. ${ }^{7-9}$ A recent study of patients from a British self help group (The National Ankylosing Spondylitis Society) suggested that the age of onset of ankylosing spondylitis is also increasing in the United Kingdom. ${ }^{10}$ This conclusion was subsequently questioned because the influence of left censoring on the data was not considered. ${ }^{11} 12$ This effect is likely to have been small on the later cohorts in the study, as the age of onset of ankylosing spondylitis continued to increase up to the last cohort studied (1981-82). There is a need, therefore, for a further evaluation of data to determine whether the age of onset of ankylosing spondylitis is increasing. ${ }^{13}$ Data obtained prospectively would avoid some of the biases inherent in the previous studies.

Data from a register of patients who attended the department of rheumatology at The London Hospital ${ }^{14}$ has allowed us to use the age at first presentation of patients with ankylosing spondylitis who attended the department over the period 1952-83 as an indirect assessment of the age at onset of disease. The age at which patients with ankylosing spondylitis presented to the London Hospital is likely to be greatly influenced by referral patterns over this period. To address these biases, patients with mechanical back pain referred to the clinic over this period were selected as a control group against which patients with ankylosing spondylitis could be compared. Biases influencing the referral of patients with ankylosing spondylitis for assessment and treatment are likely to be operating in a similar direction in patients with mechanical back pain.

\section{Patients and methods}

Subjects for this study came from outpatients with ankylosing spondylitis or mechanical back pain who had attended the department of rheumatology at the London Hospital between 1952 and 1983 and were entered in a diagnostic register. Data on the date of presentation, sex, date of birth, and diagnosis(es) were entered on the patient's first visit to the clinic. Further diagnoses were added if made at subsequent clinic visits. The register began in 1971. The date of the first presentation of earlier patients to the clinic was entered as these patients reattended.

One diagnostic code was used for ankylosing spondylitis and all these patients were included in this analysis. Patients with mechanical back pain were entered as lumbar spondylosis, backache, or back: soft tissue pain. Patients with these codes were combined as 'mechanical back pain' and a one in ten random selection of patients was taken because of the large number of patients in this diagnostic category. Data were retrieved from the register and the current analysis was undertaken using The Smart integrated software ${ }^{15}$ and Instat ${ }^{16}$ packages. Patients were grouped into three cohorts based on the year of presentation. The relationship between the year and age at first presentation for the two diagnostic categories was assessed using a Pearson correlation coefficient. A $p$ value of less than 0.05 was regarded as statistically significant.

\section{Results}

Table 1 shows that the mean age at presentation increased over the period of the study in the patients with ankylosing spondylitis but decreased in patients with mechanical back pain. There was also a marked increase in the number of patients presenting with mechanical back pain over the period. These results are reflected in table 2 , where a positive correlation is shown between the calendar year at presentation and the age at presentation of patients with ankylosing spondylitis. The $p$ value for men was significant (0.032) and there was also a similar trend for women, with an increased $t$ 
Table 1 Mean (SD) for the age at presentation of the year of presentation cohorts 1952-63, 1964-73, and 1974-83 for patients with ankylosing spondylitis and mechanical back pain

\begin{tabular}{llcl}
\hline Diagnosis & $\begin{array}{l}\text { Year of } \\
\text { presentation cohort }\end{array}$ & No of patients & $\begin{array}{l}\text { Mean (SD) age at } \\
\text { presentation (years) }\end{array}$ \\
\hline Ankylosing spondylitis & $1952-63$ & 67 & $35 \cdot 3(10 \cdot 4)$ \\
& $1964-73$ & 161 & $35 \cdot 9(13 \cdot 2)$ \\
& $1974-83$ & 229 & $38 \cdot 7(15 \cdot 0)$ \\
Mechanical back pain & $1952-63$ & 40 & $77 \cdot 8(12 \cdot 3)$ \\
& $1964-73$ & 222 & $63 \cdot 8(15 \cdot 2)$ \\
& $1974-83$ & 492 & $55 \cdot 5(16 \cdot 9)$ \\
\hline
\end{tabular}

value when men and women were combined $(t=2 \cdot 61, \quad \mathrm{p}=0 \cdot 009)$. A significant negative correlation was noted between the calendar year at presentation and age at presentation for men and women with mechanical back pain.

\section{Discussion}

Clearly the age at which patients present to a rheumatology clinic will depend upon the age at onset of the condition, its severity, and attitudes of the referring doctor and the patient to diagnosis and treatment. These comments particularly apply to patients with back pain. The ease of diagnosis of the complaint, which depends on easily applied diagnostic criteria, is relevant. The availability of specialist rheumatologists and the length of orthopaedic waiting lists will also influence the referral of patients with back pain.

We expected, before undertaking this study, that the age at presentation of patients with ankylosing spondylitis or mechanical back pain seen at the London Hospital would have decreased over the period of the study. There are various reasons for this. An expansion of rheumatology services over this period, a more positive attitude by the referring practitioner to the treatment of back pain, and the recognition of ankylosing spondylitis as a distinct and treatable spinal disorder by the referring practitioner are all likely to lead to referral of patients at a younger age. The wider availability of non-surgical forms of treatment (particularly physiotherapy) has also lead to patients being referred to rheumatology units at a less advanced stage of disease. The recognition and treatment of ankylosing spondylitis at an earlier stage of the disease may be responsible for the disappearance from rheumatic clinics of patients with gross spinal deformities. ${ }^{17}$ All of these referral biases are likely to act to reduce the age at presentation of patients with back pain over time, and this was observed in patients with mechanical back pain. The converse was noted in patients with ankylosing spondylitis.

We accept there are differences between patients with ankylosing spondylitis and mechanical back pain and the latter are not an ideal control group. Patients with mechanical back pain were older (a mean age of over 40 years for the 1952-63 year of presentation cohort). In addition, all patients with ankylosing spondylitis satisfied diagnostic criteria for this disease at the time of entry to the register. Mechanical back pain is not a diagnosis and diagnostic criteria are not available. It is a 'diagnosis' of exclusion-in particular, patients with inflammatory back pain are excluded. We accept that a few patients with ankylosing spondylitis may be included under the mechanical back pain category. As mechanical back pain is an inexact term we felt it was appropriate to include within it patients entered under the codes of lumbar spondylosis, backache, and back: soft tissue pain. Patients within these three categories are not likely to differ greatly from one another. In spite of patients with ankylosing spondylitis and mechanical back pain being dissimilar, many of the discussed referral biases are likely to apply equally to the two conditions and in the same direction, i.e. to reduce the age of patients at presentation. The mean age at presentation of the patients with ankylosing spondylitis increased over the period of the study and was most marked between the last two cohorts (1964-73 and 1974-83). Although the mean age at presentation of patients with ankylosing spondylitis is high and likely to be at least 10 years after disease onset, it continues to increase over the 31 year period of the study. The age at presentation of patients with ankylosing spondylitis or mechanical back pain to a rheumatology clinic is an inexact measure of the age at onset of the condition, but is clearly dependent upon it. An increasing age at onset of ankylosing spondylitis is the only variable that appears to explain the increasing age at presentation of these patients. The contrast between the marked fall in the age at presentation of patients with mechanical back pain, which is consistent with the anticipated changes in referral patterns, compared with the rise in the age at presentation of patients with ankylosing spondylitis strongly suggests that the age at onset of ankylosing spondylitis has increased over this period. We acknowledge that some patients with juvenile ankylosing spondylitis may have been misdiagnosed as juvenile chronic arthritis and may not have presented to the clinic until an older age. The number of these patients is likely to be small and equally distributed in all three year of presentation cohorts.

This study was prospective, in contrast to previous studies which have been cross sectional,

Table 2 Correlation coefficients $(r)$, degrees of freedom $(D F)$, and $t$ and $p$ values for men $(M)$ and women $(F)$ with ankylosing spondylitis and mechanical back pain for year of presentation versus age at presentation

\begin{tabular}{|c|c|c|c|c|c|c|}
\hline Diagnosis & Sex & $\begin{array}{l}\text { No of } \\
\text { patients }\end{array}$ & $r$ & $D F$ & t Value & p Value \\
\hline $\begin{array}{l}\text { Ankylosing spondylitis } \\
\text { Mechanical back pain }\end{array}$ & $\begin{array}{l}\mathbf{M} \\
\mathbf{F} \\
\text { Total } \\
\mathbf{M} \\
\mathbf{F} \\
\text { Total }\end{array}$ & $\begin{array}{l}350 \\
106 \\
457 \\
330 \\
360 \\
690\end{array}$ & $\begin{array}{r}0.1152 \\
0.1377 \\
0.1214 \\
-0.4140 \\
-0.3733 \\
-0.3929\end{array}$ & $\begin{array}{l}348 \\
104 \\
455 \\
328 \\
358 \\
688\end{array}$ & $\begin{array}{r}2 \cdot 16 \\
1 \cdot 42 \\
2 \cdot 61 \\
8 \cdot 24 \\
7 \cdot 61 \\
11 \cdot 21\end{array}$ & $\begin{array}{r}0.032 \\
0.159 \\
0.009 \\
<0.001 \\
<0.001 \\
<0.001\end{array}$ \\
\hline
\end{tabular}


and it thus avoided the left censoring and ascertainment biases of these studies. ${ }^{12}$ There has now been a series of independent studies (cross sectional, cross cultural, and prospective), which have all shown a similar trend of an increasing age at onset of ankylosing spondylitis either with time in Britain or on moving from developing to developed countries. This suggests that environmental factors which may trigger this disease are changing. Either the triggering 'pathogen' has been modified, the susceptible host is being exposed at a later age, or both processes may be occurring.

It has been suggested that the changing incidence of rheumatoid arthritis is due to changing patterns of the carriage of mycobacteria in the gut of patients from different countries. ${ }^{18}$ The same argument may also apply to ankylosing spondylitis where there is strong evidence that the triggering pathogen in this disease is enterically acquired. ${ }^{19}$ The organism may not be a mycobacterium. Other possibilities include salmonella, yersinia, or klebsiella organisms.

The marked increase in referrals and decline in the mean age at referral of patients with mechanical back pain may have been due to a change in referral patterns of patients with back pain as discussed previously. Conversely, this may be indirect evidence that mechanical back pain has been increasing in severity at a younger age in patients in the United Kingdom. The available data does not allow us to distinguish between these two alternatives.

In conclusion, over a 31 year period at the London Hospital rheumatology clinics there was an increasing age at presentation of patients with ankylosing spondylitis. We anticipated that because of an improvement in rheumatology services and earlier referrals, the age at presentation would fall. This was observed in patients with mechanical back pain. The increasing age of presentation in patients with ankylosing spondylitis is best explained by a rising age at onset of this condition and supports the conclusions of other studies.

We acknowledge the invaluable contribution to this study of Professor Harry Currey and the London Hospital clinicians who established and maintained the London Hospital Diagnostic Index.

1 Amor B. La spondylarthrite ankylosante est-elle moins grave en 1986? Le role des facteurs d'environment? Rev Rhum Mal Osteoartic 1987; 54: 269-71.

2 Burges-Vargas R, Naranjo A, Castillo J, et al. Ankylosing spondylitis in the Mexican Mestizo. Patterns of disease according to age at onset. $\mathcal{F}$ Rheumatol 1989; 16: 186-91.

3 Laoussadi S. Les spondylarthritides ankylosantes infantiles et juveniles [thesis]. Algeria: University of Algiers, 1969.

4 Doury P. La spondylarthrite ankylosante a debut infantile et juvenile au Maroc (Childhood and juvenile onset ankylosing
spondylitis in Morocco). Rev Rhum Mal Osteoartic 1972; 39: 453-60.

5 Deesomchok U, Tumrasuin T. A clinical study of ankylosing spondylitis in Thai patients. Proceedings of the 5 th SEAPAL Congress of Rheumatology, 1984; Thailand

6 Prakash S. Seronegative spondarthritides: a clinical, immunogenetic and scintigraphic study [Thesis]. New Delhi: All India Institute of Medical Sciences, 1981.

7 Blumberg B, Ragan C. The natural history of rheumatoid spondylitis. Medicine (Baltimore) 1956; 35: 1-31.

8 Schaller J G. Chronic childhood arthritis and the spondyloarthropathies. In: Calin A, ed. Spondyloarthropathies 1984 Orlando: Grune and Stratton: 187-208.

9 Riley M J, Ansell B M, Bywaters E G L. Radiological manifestations of ankylosing spondylitis according to age at onset. Ann Rheum Dis 1971; 30: 138-48.

10 Calin A, Elswood J, Rigg S, Skevington S M. Ankylosing spondylitis-an analytical review of 1500 patients: the changing pattern of disease. $\mathcal{F}$ Rheumatol 1988; 15: 1234-8.

11 Fries J F, Gurkipal S, Bloch D A, Calin A. The natural history of ankylosing spondylitis: is the disease really changing? $\mathcal{F}$ R heumatol 1989; 16: 860-3.

12 McCool J I. Censored data. In: Kotz S, Johnson N L, Read C, eds. Encyclopaedia of statistical sciences. New York: Wiley-Interscience, 1982: 389-96.

13 Will R K, Amor B, Calin A. The changing epidemiology of rheumatic diseases: should ankylosing spondylitis now be included? Br J R heumatol 1990; 29: 299-300.

14 Silman A, Davies P, Currey H L F, Evans S J W. Is rheumatoid arthritis becoming less severe? $f$ Chronic Dis 1983; 36: 891-7.

15 Manual revision 86a. Lenexa (KS): Innovative Software Inc. 1986.

16 Instat. Reading: Statistical Services Centre, University of Reading, 1989 .

17 Kersley G D. The first two decades of British rheumatology: a personal perspective. Ann Rheum Dis 1990; 49: 734.

18 Rook G, Lydyard P, Stanford J. Mycobacteria and rheumatoid arthritis. Arthritis Rheum 1990; 33: 431-5.

19 Nickerson C L, Luthra H S, David CS. Role of enterobacteria and HLA-B27 in spondyloarthropathies: studies with transgenic mice. Ann Rheum Dis 1990; 49: 426-33. 